\title{
DESIGN AND DEVELOPMENT OF SOLUTIONS FOR RESEARCH PROJECTS: UPPER, CITYCHAIN AND PULSE GENERATOR
}

\section{Domingo Hernández Gómez}

BISITE Research Group, University of Salamanca, Edificio Multiusos $I+D+i$, Calle Espejo 2, 37007 Salamanca, Spain domihg@usal.es

ABSTRACT: This paper describes the research work done in several projects. These projects have a different scope, from the monitoring of a city to the safety of workers in their workplaces. The solutions provided in these projects are focused on custom electronics and IoT technology.

KEYWORDS: Electronic.

\section{Introduction}

In this document my contributions to the different projects of the Bisite Group will be presented and developed. These participations have been in the projects of:

- Pulse generator for the stimulation of peripheral nerves in experimental animals

- Citychain

- Upper

\subsection{Problem description}

According to the Project, the problem to face is different: 
a) Pulse generator for the stimulation of peripheral nerves in experimental animals

Vagus nerve stimulation (VNS) has been applied in the clinic for more than two decades, but even so, the fundamental mechanisms underlying the improvement that the procedure induces in epilepsy are not entirely clear, so it is essential to continue research on the subject [1-14].

\section{b) Citychain}

The concept of Smart Cities has emerged with great intensity in recent years and its influence on our lives will continue to be increasingly evident. Some cities have begun to promote themselves as intelligent, to demonstrate their technological adaptation, attract new citizens and external investments, as well as retain those who already live there and the investments that have already been made [15-23].

Under this idea, cities play an important role, both as large data generators and as places where new services can be deployed and shown to all citizens, which impacts on their ability to generate income. Although several case studies have already demonstrated these benefits, a very low percentage of cities in the world, mainly large cities, have joined this trend and in most cases use proprietary software. The fact that this software is proprietary prevents an evolution of these management platforms, the community can develop external modules that can be coupled to the system to extend the existing functionality [24-37].

\section{c) Upper}

Safety and health in the workplace is one of the challenges that generate most concern within the business world and especially in the industrial sector. In this sense, the strategies of organizations and their teams dedicated to safety and health in the workplace, focus on training and making available to workers, the means necessary to reduce risks, which otherwise could lead to an occupational disease or an accident [38-43].

Nowadays, the available technology makes it possible to approach these problems from a similar approach, but abandoning traditional training actions and obsolete personal protective equipment (PPE), disconnected from the real environment where the working day takes place and lacking in personalization and adaptation to the particular needs of each worker. 


\subsection{Reasons}

Motivation has been common in all three projects, where the focus of progress has been on improving and making cheaper products and ways of using current technology, in an equally effective but more economical way, while at the same time trying to find a new approach to its use that provides features that are not exploited as much as possible or in a different way. Likewise, the use of new elements and technologies in all these projects has meant the need to understand and implement these technologies in the elements to be created, which has been a constant challenge that has given the team a continuous impulse to advance in the project [44-58].

\subsection{Brief description of solution}

a) Pulse generator for the stimulation of peripheral nerves in experimental animals

A PCB has been designed and created, whose function is to generate electrical impulses that are programmable, and that allows its implantation in a chronic way in the GASH/Sal. This board has been designed with connections both for the battery or power battery and for the connection of the electrodes that will be in contact with the vagus nerve.

\section{b) Citychain}

The hardware team has overseen the design and production of the plates that will be incorporated in the Citychain project. Modular plates have been created different plates with different functionalities each one, which can be joined, obtaining the combined functions of them as required.

\section{c) Upper}

Different devices have been created: a helmet, a bracelet and a belt, which have different sensors and elements incorporated, in such a way that each one of them is in charge both of collecting data from different variables and of acting in the prevention of occupational risks, depending on the values captured. 


\section{Materials and methods}

a) Pulse generator for the stimulation of peripheral nerves in experimental animals

With regard to the decision whether or not to use rechargeable batteries, it was finally decided that they would be non-rechargeable, as rechargeable batteries increased in size and price, and the estimated lifetime of certain non-rechargeable batteries (such as the one finally chosen as the best option) is sufficient for the purpose of the project.

We have tried to create the smallest possible size, whose main limitation has been the size of the battery, which is greater than desired and what could have been the PCB itself, in addition to its thickness is considerable with respect to the plate and the ideally sought [59-63].

Even so, we have created a plate of reduced size, with circular form, whose activation is carried out with a magnetic switch of which it is provided.

\section{b) Citychain}

The hardware team has overseen the design and production of the plates that will be incorporated in the Citychain project. Modular plates have been created different plates with different functionalities each one, which can be joined, obtaining the combined functions of them as required [64-68].

\section{c) Upper}

Different devices have been created: a helmet, a bracelet and a belt, which have different sensors and elements incorporated, in such a way that each one of them is in charge both of collecting data from different variables and of acting in the prevention of occupational risks, depending on the values captured [68-71].

\section{Conclusions}

Based on the results obtained so far, we can say that progress in these projects is taking shape, and the proposed objectives have been achieved satisfactorily. The Upper prototypes are almost finished, the Citychain plates are 
already functional, and the electric impulse generation plates are already being tested with the mice. Teamwork has been key to solving the problems that have arisen throughout the different processes of design, testing, creation and other phases of development.

\section{References}

1. Moung, Ervin. «A Comparison of the YCBCR Color Space with Gray Scale for Face Recognition for Surveillance Applications.» ADCAIJ: Advances in Distributed Computing and Artificial Intelligence Journal [Online], 6.4 (2017): 25-33.

2. Kethareswaran, V., \& C. SANKAR RAM. «An Indian Perspective on the adverse impact of Internet of Things (IoT).» ADCAIJ: Advances in Distributed Computing and Artificial Intelligence Journal 6.4 (2017): 35-40.

3. Cunha, Rafhael, Cleo Billa, \& Diana Adamatti. «Development of a Graphical Tool to integrate the Prometheus AEOlus methodology and Jason Platform.» ADCAIJ: Advances in Distributed Computing and Artificial Intelligence Journal 6.2 (2017): 57-70.

4. Farias, Giovani Parente, et al. «Predicting Plan Failure by Monitoring Action Sequences and Duration.» ADCAIJ: Advances in Distributed Computing and Artificial Intelligence Journal 6.4 (2017): 55-69.

5. Vera, Jefferson Stewart Espinosa. «Human rights in the ethical protection of youth in social networks-the case of Colombia and Peru.» ADCAIJ: Advances in Distributed Computing and Artificial Intelligence Journal 6.4 (2017): 71-79.

6. Casado-Vara, R., Martin-del Rey, A., Affes, S., Prieto, J., \& Corchado, J. M. (2020). IoT network slicing on virtual layers of homogeneous data for improved algorithm operation in smart buildings. Future Generation Computer Systems, 102, 965-977.

7. Mateen, Abdul, et al. «Secure data access control with perception reasoning.» ADCAIJ: Advances in Distributed Computing and Artificial Intelligence Journal 7.1 (2018): 13-28.

8. Teixeira, Eduardo Porto, Eder Goncalves, \& Diana F. Adamatti. «Ulises: A AgentBased System For Timbre Classification.» ADCAIJ: Advances in Distributed Computing and Artificial Intelligence Journal 7.1 (2018): 29-40.

9. Van Haare Heijmeijer, Alexis, \& Gleifer Vaz Alves. «Development of a Middleware between SUMO simulation tool and JaCaMo framework.» ADCAIJ: Advances in Distributed Computing and Artificial Intelligence Journal 7.2: 5-15. 
10. Glaeser, Stefania da Silveira, et al. «Modeling of Circadian Rhythm under influence of Pain: an approach based on Multi-agent Simulation.» ADCAIJ: Advances in Distributed Computing and Artificial Intelligence Journal 7.2 (2018): 17-25.

11. De Melo, Maximilian Jaderson, et al. «Robust and adaptive chatter free formation control of wheeled mobile robots with uncertainties.» ADCAIJ: Advances in Distributed Computing and Artificial Intelligence Journal 7.2 (2018): 27-42.

12. Ribeiro, Catarina, et al. «Customized normalization clustering meth-odology for consumers with heterogeneous characteristics.» ADCAIJ: Advances in Distributed Computing and Artificial Intelligence Journal 7.2 (2018): 53-69.

13. Becerril, Anahiby Anyel. «The value of our personal data in the Big Data and the Internet of all Things Era.» ADCAIJ: Advances in Distributed Computing and Artificial Intelligence Journal 7.2 (2018): 71-80.

14. Garcia, Ana Cristina Bicharra, \& Adriana Santarosa Vivacqua. «ACoPla: a Multiagent Simulator to Study Individual Strategies in Dynamic Situations.» ADCAIJ: Advances in Distributed Computing and Artificial Intelligence Journal 7.2: 81-91.

15. Casado-Vara, R., Novais, P., Gil, A. B., Prieto, J., \& Corchado, J. M. (2019). Distributed continuous-time fault estimation control for multiple devices in IoT networks. IEEE Access, 7, 11972-11984.

16. Machón-González, I., López-García, H., \& Calvo-Rolle, J. L. (2010, July). A hybrid batch SOM-NG algorithm. In The 2010 international joint conference on neural networks (IJCNN) (pp. 1-5). IEEE.

17. Rafael Cauê Cardoso, Rafael Heitor Bordini. (2017) A Multi-Agent Extension of a Hierarchical Task Network Planning Formalism. ADCAIJ: Advances in Distributed Computing and Artificial Intelligence Journal (ISSN: 2255-2863), Salamanca, v. 6, n. 2

18. Enyo Gonçalves, Mariela Cortés, Marcos De Oliveira, Nécio Veras, Mário Falcão, Jaelson Castro (2017). An Analysis of Software Agents, Environments and Applications School: Retrospective, Relevance, and Trends. ADCAIJ: Advances in Distributed Computing and Artificial Intelligence Journal (ISSN: 2255-2863), Salamanca, v. 6, n. 2

19. Eduardo Porto Teixeira, Eder M. N. Goncalves, Diana F. Adamatti (2017). Ulises: A Agent-Based System For Timbre Classification. ADCAIJ: Advances in Distributed Computing and Artificial Intelligence Journal (ISSN: 2255-2863), Salamanca, v. 6, n. 2

20. Lucas Fernando Souza de Castro, Gleifer Vaz Alves, André Pinz Borges (2017). Using trust degree for agents in order to assign spots in a Smart Parking. ADCAIJ: 
Advances in Distributed Computing and Artificial Intelligence Journal (ISSN: 2255-2863), Salamanca, v. 6, n. 2

21. Aversa, R., Petrescu, R. V., Akash, B., Bucinell, R., Corchado, J., Berto, F., ... \& Petrescu, F. I. (2017). Kinematics and forces to a new model forging manipulator. American Journal of Applied Sciences, 14(1), 60-80.

22. Li, T., Sun, S., Bolić, M., \& Corchado, J. M. (2016). Algorithm design for parallel implementation of the SMC-PHD filter. Signal Processing, 119, 115-127.

23. Corchado, J. M., Aiken, J., Corchado, E. S., \& Fdez-Riverola, F. (2005). Evaluating the air-sea interactions and fluxes using an instance-based reasoning system. AI Communications, 18(4), 247-256.

24. Costa, Â., Novais, P., Corchado, J. M., \& Neves, J. (2011). Increased performance and better patient attendance in an hospital with the use of smart agendas. Logic Journal of IGPL, 20(4), 689-698.

25. Rodríguez, S., de La Prieta, F., Tapia, D. I., \& Corchado, J. M. (2010, June). Agents and computer vision for processing stereoscopic images. In International Conference on Hybrid Artificial Intelligence Systems (pp. 93-100). Springer, Berlin, Heidelberg.

26. Corchado, J. M., Corchado, E. S., \& Pellicer, M. A. (2004, September). Design of cooperative agents for mobile devices. In International Conference on Cooperative Design, Visualization and Engineering (pp. 205-212). Springer, Berlin, Heidelberg.

27. Corchado, J. M., Laza, R., Borrajo, L., Yañez, J. C., De Luis, A., \& Gonzalez-Bedia, M. (2003, July). Agent-based web engineering. In International Conference on Web Engineering (pp. 17-25). Springer, Berlin, Heidelberg.

28. Fdez-Riverola, F., \& Corchado, J. M. (2003). Forecasting red tides using an hybrid neuro-symbolic system. AI Communications, 16(4), 221-233.

29. González-Briones, A., Prieto, J., De La Prieta, F., Herrera-Viedma, E., \& Corchado, J. (2018). Energy optimization using a case-based reasoning strategy. Sensors, 18(3), 865 .

30. Díaz, F., Fdez-Riverola, F., Glez-Peña, D., \& Corchado, J. M. (2006, September). Using fuzzy patterns for gene selection and data reduction on microarray data. In International Conference on Intelligent Data Engineering and Automated Learning (pp. 1087-1094). Springer, Berlin, Heidelberg.

31. Koetsier, J., Corchado, E., MacDonald, D., Corchado, J., \& Fyfe, C. (2004, June). Kernel maximum likelihood hebbian learning. In International Conference on Computational Science (pp. 650-653). Springer, Berlin, Heidelberg.

32. Pavón, J., \& Corchado, J. (2004). Agents for the web. International journal of Web engineering and technology, 1(4), 393-396. 
33. Fdez-Riverola, F., Díaz, F., Borrajo, M. L., Yáñez, J. C., \& Corchado, J. M. (2005, August). Improving gene selection in microarray data analysis using fuzzy patterns inside a cbr system. In International Conference on Case-Based Reasoning (pp. 191-205). Springer, Berlin, Heidelberg.

34. Fernández-Riverola, F., \& Corchado, J. M. (2003, November). Employing tsk fuzzy models to automate the revision stage of a cbr system. In Conference on Technology Transfer (pp. 302-311). Springer, Berlin, Heidelberg.

35. Corchado, J. M., \& Aiken, J. (1998). Expert system for modelling water masses. In WORKSHOP ON DATA MINING. GLASGOW, SCOTLAND.

36. Corchado, J. M., \& Aiken, J. (1998). Neuro-symbolic reasoning for real time oceanographic problems. In CONFERENCE ON DATA MINING. IEE, SAVOY PLACE, LONDON.

37. Corchado, J. M. (1998). Models for integrating artificial intelligence approaches. DOCTORAL CONSORTIUM ON KNOWLEDGE DISCOVERY AND DATA MINING. PAISLEY, UK.

38. Borrajo, M. L., Corchado, J. M., Yáñez, J. C., Fdez-Riverola, F., \& Díaz, F. (2005, August). Autonomous internal control system for small to medium firms. In International Conference on Case-Based Reasoning (pp. 106-121). Springer, Berlin, Heidelberg.

39. Fdez-Riverola, F., Díaz, F., \& Corchado, J. M. (2004, November). Applying rough sets reduction techniques to the construction of a fuzzy rule base for case based reasoning. In Ibero-American Conference on Artificial Intelligence (pp. 83-92). Springer, Berlin, Heidelberg.

40. Corchado, J., \& Lees, B. (1998). Case based reasoning opportunities and technologies. In CONFERENCE ON KNOWLEDGE DISCOVERY. IEE, SAVOY PLACE, LONDON.

41. Corchado, J., \& Lees, B. (1998). Artificial neural networks in pattern recognition: multicollinearity and heterocedasticity. In COLLOQUIUM ON KNOWLEDGE DISCOVERY. LONDON, UK.

42. Corchado, J., \& Lees, B. (1998). An overview of intelligent frameworks. In COLLOQUIUM ON INTELLIGENT SYSTEMS. IEE, LONDON, UK.

43. Corchado, J. M., \& Lees, B. (1998). Probis: Modelling intelligence with hybrid systems. In WORKSHOP ON DATA MINING. University of GLASGOW, SCOTLAND, UK.

44. Corchado, J. (1998). Real time forecast with intelligent systems. In CONFERENCE ON KNOWLEDGE DISCOVERY. IEE, SAVOY PLACE, LONDON. 
45. Corchado, J. M. (1997). Bdi multiagent hybrid architecture for project management. In IEEE COLLOQUIUM ON KNOWLEDGE DISCOVERY AND DATA MINING. LONDON ENGLAND.

46. Corchado, J. M. (1997). System for decision making: a practical case. In CONFERENCE ON KNOWLEDGE DISCOVERY AND DATA MINING. IEE, LONDON, UK.

47. Corchado, J. (1995). Cbr systems, an overview. In INTERNATIONAL CONFERENCE ON INTELLIGENT SYSTEMS. LONDON, ENGLAND, UK.

48. Li, T., Sun, S., Corchado, J. M., \& Siyau, M. F. (2014, July). A particle dyeing approach for track continuity for the SMC-PHD filter. In 17th International Conference on Information Fusion (FUSION) (pp. 1-8). IEEE.

49. Casado-Vara, R., Prieto, J., De la Prieta, F., \& Corchado, J. M. (2018). How blockchain improves the supply chain: Case study alimentary supply chain. Procedia computer science, 134, 393-398.

50. Corchado, J. M. (1996). Case-base reasoning recommendation system. In IEEE COLLOQUIUM ON KNOWLEDGE DISCOVERY. LONDON, UK.

51. Corchado, J. M. (1995). Neuro-symbolic reasoning-a solution for complex problemas. In INTERNATIONAL CONFERENCE ON INTELLIGENT SYSTEMS. LONDON, UK.

52. Corchado, J. M. (1995). Multi agent tools: a case study. In IEEE COLLOQUIUM ON KNOWLEDGE DISCOVERY. LONDON ENGLAND, UK.

53. Casado-Vara, R., Prieto-Castrillo, F., \& Corchado, J. M. (2018). A game theory approach for cooperative control to improve data quality and false data detection in WSN. International Journal of Robust and Nonlinear Control, 28(16), 50875102.

54. Corchado, J. M., \& Lees, B. (2001). Adaptation of cases for case based forecasting with neural network support. In Soft computing in case based reasoning (pp. 293-319). Springer, London.

55. Rodriguez, J. M. C. (2000). Neuro-symbolic model for real-time forecasting problems (Doctoral dissertation, University of Paisley).

56. Casado-Vara, R., Chamoso, P., De la Prieta, F., Prieto, J., \& Corchado, J. M. (2019). Non-linear adaptive closed-loop control system for improved efficiency in IoT-blockchain management. Information Fusion, 49, 227-239.

57. Li, T., Sun, S., Corchado, J. M., \& Siyau, M. F. (2014, July). Random finite setbased Bayesian filters using magnitude-adaptive target birth intensity. In 17th International Conference on Information Fusion (FUSION) (pp. 1-8). IEEE. 
58. Rodríguez, S., Gil, O., De La Prieta, F., Zato, C., Corchado, J. M., Vega, P., \& Francisco, M. (2010, May). People detection and stereoscopic analysis using MAS. In 2010 IEEE 14th International Conference on Intelligent Engineering Systems (pp. 159-164). IEEE.

59. Guillén, J. H., del Rey, A. M., \& Casado-Vara, R. (2019). Security Countermeasures of a SCIRAS Model for Advanced Malware Propagation. IEEE Access, 7 , $135472-135478$.

60. Corchado, J. M. (1996). Artificial intelligence models: composed systems as a solution. In IEEE COLLOQUIUM ON KNOWLEDGE DISCOVERY. LONDON ENGLAND, UK.

61. Casado-Vara, R., De la Prieta, F., Rodriguez, S., Prieto, J., \& Corchado, J. M. (2018, June). Cooperative Algorithm to Improve Temperature Control in Recovery Unit of Healthcare Facilities. In International Symposium on Distributed Computing and Artificial Intelligence (pp. 49-62). Springer, Cham.

62. Corchado, J. M. (1995). Hybrid cbr system for real-time temperature forecasting in the ocean. In IEEE COLLOQUIUM ON KNOWLEDGE DISCOVERY. LONDON, UK.

63. Casado-Vara, R., de la Prieta, F., Prieto, J., \& Corchado, J. M. (2018, November). Blockchain framework for IoT data quality via edge computing. In Proceedings of the 1st Workshop on Blockchain-enabled Networked Sensor Systems (pp. 19-24). ACM.

64. Gil, A. B., De la Prieta, F., \& Rodríguez, S. (2011). Automatic Learning Object Extraction and Classification in Heterogeneous Environments. In Highlights in Practical Applications of Agents and Multiagent Systems (pp. 109-116). Springer, Berlin, Heidelberg.

65. Rodríguez, S., Tapia, D. I., Sanz, E., Zato, C., de la Prieta, F., \& Gil, O. (2010, July). Cloud computing integrated into service-oriented multi-agent architecture. In International Conference on Information Technology for Balanced Automation Systems (pp. 251-259). Springer, Berlin, Heidelberg.

66. Di Mascio, T., Vittorini, P., Gennari, R., Melonio, A., De La Prieta, F., \& Alrifai, M. (2012, July). The Learners' User Classes in the TERENCE Adaptive Learning System. In 2012 IEEE 12th International Conference on Advanced Learning Technologies (pp. 572-576). IEEE.

67. Garcia, R. F., Rolle, J. L. C., Castelo, J. P., \& Gomez, M. R. (2014). On the monitoring task of solar thermal fluid transfer systems using NN based models and rule based techniques. Engineering Applications of Artificial Intelligence, $27,129-136$. 
68. Prieto, J., Alonso, A. A., la Rosa, de, R., \& Carrera, A. (2014). Adaptive Framework for Uncertainy Analysis in Electromagnetic Field Measurements. Radiation Protection Dosimetry. doi:10.1093/rpd/ncu260

69. Prieto, J., Bahillo, A., Mazuelas, S., Blas, J., Fernández, P., \& Lorenzo, R. M. (2008). RTS/CTS mechanism with IEEE 802.11 for indoor location. Presented at the NAV08/ILA37, The Navigation Conference \& Exhibition.

70. Prieto, J., Bahillo, A., Mazuelas, S., Fernández, P., Lorenzo, R. M., \& Abril, E. J. (2012a). Self-Calibration of TOA/Distance Relationship for Wireless Localization in Harsh Environments. Presented at the 2012 IEEE International Conference on Communications (ICC 2012).

71. Prieto, J., Bahillo, A., Mazuelas, S., Lorenzo, R. M., Blas, J., \& Fernández, P. (2009a). Adding indoor location capabilities to an IEEE 802.11 WLAN using real-time RTT measurements (pp. 113-119). IEEE Press. Retrieved from http:// dl.acm.org/citation.cfm? $\mathrm{id}=1689059.1689083 \&$ coll $=\mathrm{DL} \& \mathrm{dl}=\mathrm{GUIDE} \& \mathrm{CFID}=$ $647274630 \&$ CFTOKEN $=45917612$ 
